\title{
TEXTUAL ORGANISATION AND LINGUISTIC FEATURES IN APPLIED LINGUISTICS RESEARCH ARTICLES: MOVING FROM INTRODUCTION TO METHODS
}

\author{
Attapol Khamkhien \\ Centre for Applied Linguistics, University of Warwick, UNITED KINGDOM, \\ email: a.khamkhien@warwick.ac.uk
}

\begin{abstract}
Writing and publishing research articles (RAs) in English is crucial because an RA is considered as one of the channels to communicate among researchers and scholars worldwide. Research publication has become one of the requirements for Thai graduate students before graduation; however writing for publication is a daunting task to them as it requires substantial writing skills to ensure that researchers can efficiently present research findings and express themselves in response to textual convention and academic community. This paper centres on the rhetorical structures and linguistic features commonly used in the Introduction and Methods sections of the RA genre as written in a particular set of journals. Inspired by Swales' analytical framework $(1990 ; 2004)$ and work by Biber, Conner and Upton's (2007) steps of conducting a move analysis, this study examined $25 \mathrm{RA}$ Introduction and Methods sections in the field of applied linguistics. These RAs were analysed by genre analysis into 'moves' and 'steps'. The results revealed that each section displayed a generic pattern, comprising a series of moves and steps. Lexicogrammatical features associated with a communicative function were also identified. Pedagogically, the findings generated by this study could be useful for teaching students how to write scholarly publications in EAP classrooms. The structural patterns and linguistic features found to functionally interact with one other may facilitate the understanding of novice writers and Thai graduates of published research articles in these sections. Moreover, the rhetorical patterns generated by this study might be meaningful for teachers in implementing relevant reading and writing materials for advanced learners to improve their writing skills to effectively disseminate discoveries in their fields.
\end{abstract}

Keywords: Research articles, Introduction, Methods, genre analysis, rhetorical structures.

\section{INTRODUCTION}

Writing for scholarly publications in peer-reviewed journals is crucial. Scholars and researchers from various academic disciplines have been under tremendous pressure to not only get access to information, but also share and disseminate their research findings and new scientific discoveries through English in prestigious journals. Consequently, since RAs represent the preferred medium of exchanging knowledge among members of the academic community (Flowerdew, 1999), researchers and scholars are pushed to successfully participate and meet the standard criteria and conventions of writing practices for academic and professional reasons.

As stated by Canagarajah (1996) and Flowerdew (1999), without having received formal training in how to write academic English, publishing RAs in peer-reviewed journals is somewhat difficult for many non-native 
speaking researchers. The task of writing RAs in general is also considered relatively daunting and challenging for most novice writers. To publish an RA successfully, writing skills are essential to ensure that writers can efficiently and successfully express themselves academically. Cook (1990) and MaCarthy (1991) suggest that to be able to understand and produce RAs, writers need to make use of both macro and micro level genre knowledge. The macro knowledge of an RA genre starts with the knowledge of the structural organisation of the discourse units, before moving onto lexical and grammatical features used in the text. In contrast, the micro knowledge of the RA which is the bottom-up knowledge refers to the smallest units of discourse, such as grammatical items, and moving onto more general features such as sentences, discourse units, and structural organisations of the discourse units. In other words, to write effectively, writers need to have knowledge of the genre and linguistic characteristics, including lexico-grammatical features, rhetorical organisation, communicative functions, and content (Hyland, 2004).

However, Thai novice authors and graduate students still often face serious problems when they attempt to publish their RAs in English in refereed journals, particularly international journals (Kanoksilapatham, 2007). Specifically, Thai graduate students in the social sciences field seem to have some difficulties in publishing in English for a number of reasons. First, they need to understand how to conform to the overall organisation, and how to use certain expressions and vocabularies commonly employed in their respective discourse communities and academic disciplines. Second, the number of international journals in social sciences is relatively small compared to those in the sciences (Flowerdew, 2001). Hence, it is inevitable that the ability to read and write an RA in English is pivotal for novice authors in general, and for Thai graduate students in particular, and for handling academic writing tasks encountered in a higher education setting.

Through the widely used Create a Research Space Model (CARS) proposed by Swales (1990; 2004), a multitude of genre-based studies have been conducted on the macro-structure of RAs and have revealed that different components and lexico-grammatical features were found in the four sections of RAs (Introduction, Methods, Results, and Discussion or IMRD) and different fields of discipline (e.g. Basturkmen, 2012; Bruce, 2008; Kanoksilapatham, 2011; 2012; Lim, 2006; Ozturk, 2007; Yang \& Allison, 2003). These studies also acknowledge the increasingly important role of RAs written in English. The results of these studies generally seem to indicate that the rhetorical structure of the RA is to some extent dependent on the discipline to which it belongs and the linguistic and/or cultural context in which it is written. However, particular attention in this line of research has been paid to the analysis of the Introduction section in several disciplines, whereas the Methods section seems to have attracted the least attention (Duenas, 2007).

The purpose of this article is an attempt to make a link between the generic structure of the Introduction and Methods sections of RAs, providing detailed rhetorical and lexico-grammatical realisations in applied linguistics RAs. It is hoped that, pedagogically, the findings obtained will help facilitate the teaching/training of Thai graduate students and novice scholars to construct these two sections in a manner conforming to the expectations of their respective academic communities, both rhetorically and linguistically.

\section{LITERATURE REVIEW}

\subsection{Swales' Framework of Move and Step Analysis}

Swales' framework was originally designed to help non-native speakers of English in a university setting master the macro level of organisational structures and the micro level of linguistic features which are conventionally used in texts required in their disciplines and professions (Hyon, 2002; Swales, 1990). According to Biber et al. (2007, p. 15), Swales' move analysis is regarded as a specific approach to genre analysis. It was developed as a top-down or macro approach to demystify the discourse structure of texts from a genre. The basic aim of move analysis is to consider and describe texts as a sequence of "moves", where each move presents a stretch of text serving a particular communicative function. Each move, therefore, not only has its own purpose but also contributes to the overall communicative purpose of the genre.

In conducting a move analysis, researchers segment texts into moves based on their communicative purpose, as it is believed that the overall discourse structure of a text can be described in relation to the sequence of move types. Each move contains a number of elements with which the move is realised. These constituent elements are referred to as "steps" by Swales (1990) or "strategies" by Bhatia (1993). The steps of a move primarily function to achieve the purpose of the move to which it belongs (e.g., Bhatia, 1993; Swales, 1990; 2004). In short, the main objective of move-based studies on a type of text is to identify the organisation of texts, by capturing the prevalent types of moves and steps, and how these are organised in a particular text. 
Swales $(1990 ; 2004)$ proposed a version of the CARS model which has been the predominant analytical tool used in the analysis of the Introduction component of RAs. It is used to describe the macro structure of RAs Introduction, consisting of three moves. Each of the moves is obligatory and minimally consists of one component step. The following figure summarises the CARS model as proposed in Swales (2004).

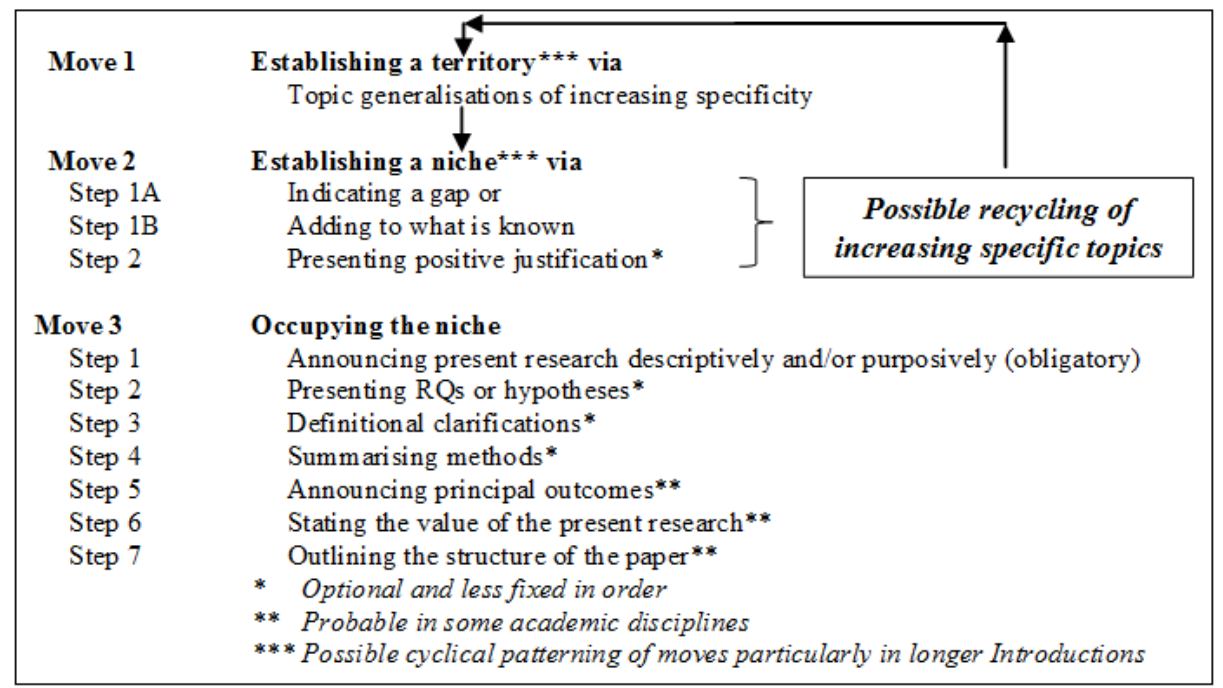

Fig. 1: Swales' 2004 revised model for RA Introductions.

The model has been subsequently validated in RA Introductions across several disciplines (e.g., Samraj, 2002 in wildlife behaviour and biology conservation; Kanoksilpatham, 2011; 2012 in civil engineering; Ozturk, 2007 in second language acquisition and second language writing). As an extension, the model was also adapted and used to analyse other internal sections of RAs in academic disciplines, e.g., Brett (1994) in the Results section; Peacock (2011) in the Methods sections in eight disciplines; Lim (2006) in the Method sections of management RAs; Yang and Allison (2003) in Results and Discussion sections of applied linguistics RAs; and Nwogu (1997) in the Discussion section of medical articles. The findings from these studies have helped us recognise that awareness of rhetorical organisation of texts is helpful, providing the schema of what information elements or moves is presented. These studies, however, have demonstrated that each section of RAs has its own structural organisation and is probably discernible with regard to disciplinary variation. Furthermore, patterns of lexical and grammatical features frequently used in research articles also usually vary according to the writers' English proficiency and writers' idiosyncrasy.

\section{METHODOLOGY}

\subsection{Dataset Compilation}

25 RAs in applied linguistics from important journals in the Thai context were systematically compiled to ensure as far as possible that the datasets are representative of the genre. To minimise the subjectivity of the researcher and enhance the validity of the analysis regarding a journal selection, the journals indexed in the Thai Citation Index ( $\mathrm{TCl}$ ) database were carefully selected. Based on the classification of the TCI database, the journals were classified in the first and second group of the database, representing the quality of the journals (Sombatsompop et al., 2012). These selected journals were published during the years 2012 and 2013.

To systematically select 25 RAs from each of the journals, firstly, RAs were chosen whose contents appear to relate to studies in the field of applied linguistics (e.g. teaching and learning, second language acquisition, discourse analysis, foreign language teaching, testing and assessment, etc.). Secondly, only empirical research articles, consisting of Introduction, Methods, Results, and Discussion and/or Conclusion (IMRD) sections were compiled to control the reliability of the textual analysis. Thirdly, the first language of the authors of these RAs for the data was not taken into account in this study. Lastly, only the sections of Introduction and Methods were analysed in this study.

\subsection{Dataset Analysis}

The data collected and complied were analysed using Swales' analytical framework and the steps from Biber et al. (2007) to perform a move analysis to determine the sub-units of 'moves' and 'steps'. Linguistic features 
found in move and step instances were analysed to explore their communicative function in the text segments. To determine the potential status of each move, the frequencies of occurrence of the individual moves identified were recorded. Inter-coder reliability for identifying moves between the researcher and the coders across the texts was attained, with an average rate for the introduction section of $89.30 \%$ and the Methods section of $92.14 \%$. Upon completion of the analysis of each section, an overall structural organisation for the section was identified, showing the typical sequence of moves and their constituents found in the dataset.

\section{RESULTS}

In the presentation of the texts below, parenthetical citations appearing in the original texts are replaced by (Ref) for space-saving purposes. Distinct lexico-grammatical features in text segments, which seem to particularly indicate communicative functions, are highlighted in boldface, because they offer semantically driven clues on how moves are identified with regard to their communicative function. However, the original division of paragraphs has been preserved. The names of the journals taken into the analysis are also abbreviated as JLA, SCOJ, SJSH, SPPJ, NET, JES, LEA, and VEJ.

\subsection{Features of Moves and Steps and Their Frequency in Introduction Sections}

The analysis reveals that the Introduction section in applied linguistics research articles consists of four move types in a pattern similar, but not identical, to that proposed by Swales. The following sections describe the features of each move and step identified in the analysis.

Move 1: Establishing the topic being studied is the first move to occur in the initial position of the Introduction section. As suggested by its name, this move is generally used to ensure that readers can determine if the research is of relevance to them and so worth reading, and to claim its significance of further exploration in the field. Move 1 consists of three possible steps as follows:

Move 1, Step 1: Announcing the importance of the field is generally used to present the importance of the research topic being studied. This move/step functions as a statement of current knowledge, highlighting the importance of the research topic.

Reading entirely in English is particularly important for Thai university EFL students because of the large number of course texts, references and internet materials appearing in that language. [JLA 1]

As can be clearly seen, the author can introduce the topic of the study and claim that it is a significant area of study through the use of emphatic lexical items (important, key factor) and amplifiers (particularly important). Noticeably, evaluative adjectives are used as predicative adjectives. More interestingly, the current state of the topic is signalled by the use of the present verb tense and present perfect, showing that the topic under investigation is still of potential interest to the readers.

Move 1, Step 2: Making topic generalisation is invariably present and usually opens the section. This can occur elsewhere in the Introduction section. According to Swales (2004), this step can take a variety of forms, but it generally falls into one of two categories: statements about knowledge that are generally known in the field or practice and statements about phenomena.

Reading involves a number of cognitive processes; therefore, awareness and understanding of these processes help readers perform their reading better. [SPJ 1]

Move 1, Step 2 indicates the statement represents what is generally known or accepted in the field. Therefore, reference to a particular scholar is not made. The use of present tense verbs, be they active or passive (involves, is complicated, can be associated), is the dominant linguistic feature used to accomplish this move/step; expressing a statement is assumed to be known to, or agreed by, discourse community members including potential readers and those who are interested in the topic. The function of this move is similar to Wharton's (2006) comment, asserting that by stating initial information in a brief form, writers are signalling that they believe this information to be shared knowledge in the community.

Move 1, Step 3: Reviewing previous research in which previous studies deemed by the authors to be relevant to the topic are presented to help establish the claims that the authors want to make. This move/step is always recognised through clusters of citations intermingled throughout the text.

A number of studies on modified interaction or negotiation for meaning (Ref) suggested that the process of negotiating for meaning is facilitative of L2 acquisition. [NET 2]

A unique feature of this step is the presence of citations or references (Ref). Move 1, Step 3 is relatively specific, as all realisations of the move refer to several previous studies (a number of studies). This 
move/step is widely found in the Introduction section because assessing previous research in the literature can possibly enhance the author's credentials as a possessor of knowledge.

Move 2: Presenting statement of problems/needs is used to attract the attention of readers by mentioning some problematic issue, leading to the necessity and/or needs to conduct the study in question. It is obvious that words, phrases, or negation patterns conveying negative connotations are usually employed in this move in order to present key characteristics of a particular problem. Regardless of its position, this move could occur once in the Introduction section or could be interrupted by another move.

\begin{abstract}
Although the importance of reading is well-recognized, many Thai university EFL students' English reading comprehension skill is still poor. This indicates difficulties in fulfilling the demands of their studies. [JLA 1]
\end{abstract}

In the instance above, the author tries to convince readers that the problem being stated in the paper is relevant by pointing out how the situation or problem arises. The use of present tense verbs (is, indicates) is prominent in Move 2, highlighting the existence of the current problems, which are thus worth investigating in the study. In this regard, the distinct use of words that have negative meanings (difficulties) is the main strategy commonly used to accomplish this purpose. Contradiction connectors (although) are used to connect the ideal situation previously mentioned to the current situation that falls short of the goal.

Move 3: Establishing a niche is used to draw attention to a weakness or gap in the literature. This third move found seems to be a common strategy used in order to prepare readers by addressing or identifying gaps in previous studies, pinpointing how inadequate and problematic they are. Move 3 in this study is typically realised through two possible steps as follows:

Move 3, Step 1: Indicating research gaps serves to express critical comments addressing a current gap in existing research. This move/step is used most to pinpoint some limitations or weaknesses in the existing literature.

No study has been reported about the type of processing approach of English language by learners of non-romance languages in general and Persian in particular. [LEA 6]

Move 3, Step 1 is employed as a strategy to mention that previous research studies suffer from some limitations. The main function of this move is therefore to create a gap or to identify more specific areas of research which require further investigation after assessing or reviewing the literature. A number of lexical entries are used in this move involving a set of lexical words including negative quantifiers and evaluations such as indefinite adjectives or pronouns, negation devices (no, few), and adversative connectors. In this regard, the use of the adversative connector indicates that existing knowledge bears some limitations, and thus remains to be explored.

Move 3, Step 2: Presenting positive justification serves to support the need for the existence of the study, specifying the expected benefits obtained from the work being reported.

Considering these studies, examining the components of student engagement is essential to successfully engage students even if following the school curriculum is required in some schools. [NET 1]

The linguistic features of present tense verbs (is) and lexical items that indicate that research should be conducted are commonly used, indicating that immediate attention on the topic being studied is needed. Moreover, the authors used lexical items with positive reasons in reporting the study (essential) to assist them in reinforcing the research topic which they intend to investigate.

Move 4: Introducing the present study is a means to introduce the work which will fill in the gap earlier indicated in Move 3. Therefore, Move 4 is closely connected to Move 3. With regard to the position of this move, it usually ends the Introduction section. Move 4 could be realised by four possible steps as follows:

Move 4, Step 1: Stating objectives explicitly gives the purpose for the research being reported. This is in line with Samraj's (2002) study which shows that presenting research goals is present and generally elaborated in all the wildlife behaviour Introductions that she studied.

This research aimed to study whether the training in part of speech identification and dictionary use would help students translate better and find out what factors they thought affect their ability to translate and how they feel about the training. [JLA 2]

The most frequent signal in this step to state the objectives is the use of deictic references to the texts, including demonstrative adjectives (this), and specific determiners (the) followed mainly by common nouns 
(study, research). Impersonal stereotypical phrases (the aim of this study, this study aimed) were also used. The noun (researchers) is used to express identity and inform readers of their involvement of the research.

Move 4, Step 2: Listing research procedures serves to briefly describe methodological procedures and/or experimental frameworks adopted by the studies.

However, in this study three different two-way communication tasks were selected; problem-solving tasks, information gap tasks and story-telling task. [NET 2]

Step 2 of Move 4 is normally longer than mere one-sentence announcements. This move/step is used to describe selectively only major procedural features in Introduction sections because it is possible that it depends on what the authors consider to be the main features of the study. Some lexical signals used to express Move 4, Step 2 include expressions related to research procedures and research tools (problemsolving tasks, information gap tasks, story-telling task). Activity verbs describing research activities (were selected) are also used to present methodological procedures. The choice of past simple tenses also indicates that the methodology was carefully selected in the study being reported.

Move 4, Step 3: Claiming research value serves to inform readers of the value of the research being presented. Functionally, this move/step discusses the research findings from several perspectives, including implications, significance, interpretations or contributions of the study being reported.

The results of this study contribute some empirical evidence in an attempt to raise awareness of a test bias which has been overlooked in many ESL/EFL contexts. [JES 1]

The example above indicates that this move/step is used to express the contribution of the results of the studies and their practical implications. Some linguistic features used to accomplish this move/step include cognitive nouns (awareness) and likelihood nouns (empirical evidence), and predicative and possibility modals. Deictic elements, including specific determiners or demonstrative adjectives (this) followed by common nouns (study) and formulaic structures (the results of this study) are frequently used in the texts.

Move 4, Step 4: Indicating research questions, if present, may be the last move to end the Introduction. As found in some Introductions, the authors explicitly state the purposes of the study in the form of research questions under the new specific subheading, not the Introduction. However, those instances in other subheadings were excluded from the analysis.

In particular, this investigation tried to answer the following questions.

1) How do students respond, in terms of attention/awareness, action and attitude, to WCF?

2) Are there significant differences in students' responses to the three types of WCF, namely direct, indirect, and coded corrective feedback? [LEA 2]

It is clear that the aim or goal of a study in this move/step can be formulated as research questions. Specifically, as can be seen from the above example, the research questions found in Introduction sections are stated directly (to answer the following questions), and are generally listed.

Table 1: Frequency of occurrence of moves and steps in research article Introduction sections.

\begin{tabular}{lcc}
\hline \multicolumn{1}{c}{ Move/Step } & \multicolumn{2}{c}{ Research Articles (N = 25) } \\
\cline { 2 - 3 } & Freq. & Percent \\
\hline Move 1: Establishing the topic being studied & $\mathbf{2 5}$ & $\mathbf{1 0 0 \% ^ { * }}$ \\
Step 1: Announcing the importance of the field & 13 & $52 \%$ \\
Step 2: Making topic generalisation & 22 & $88 \%$ \\
Step 3: Reviewing previous studies & 23 & $92 \%$ \\
Move 2: Presenting statement of problems/needs & $\mathbf{8}$ & $\mathbf{3 2 \%} \%^{\star * \star}$ \\
Move 3: Establishing a niche & $\mathbf{2 3}$ & $\mathbf{9 2 \%}$ \\
Step 1: Indicating research gaps & 14 & $56 \%$ \\
Step 2: Presenting positive justification & 9 & $36 \%$ \\
Move 4: Introducing the present study & $\mathbf{2 5}$ & $\mathbf{1 0 0 \% *}$ \\
Step 1: Stating objective(s) & 25 & $100 \%$ \\
Step 2: Summarising research methods & 5 & $20 \%$ \\
Step 3: Claiming research values & 9 & $36 \%$ \\
Step 4: Indicating research questions & 2 & $8 \%$ \\
\hline${ }^{*}=$ Obligatory, ${ }^{* *}=$ Usual, ${ }^{* \star *}$ Optional & & \\
\hline
\end{tabular}


As shown, Moves 1 and 4 were always present (100\%) in the Introduction section, whilst Move 3 occurred less frequently (92\%). Move 2 was rarely found (32\%), however, compared with other moves in the Introduction sections of the applied linguistics RAs. Based on the cut-off point of the occurrence rate of the move, with the exception of Move 2, all moves identified appeared in all 25 Introductions, resulting in a high frequency of occurrence ranging from $92 \%$ to $100 \%$. Thus, Moves 1 and 4 were considered obligatory, while Move 3 appears quite frequently in the section. Move 2 was considered optional in performing its communicative function in the Introduction section.

\subsection{Features of Moves and Steps and Their Frequency in Methods Sections}

The Methods sections of 25 applied linguistics RAs consist of a set of five distinctive moves organised into a particular pattern. The following sections present common features and linguistic characteristics of moves in the Methods section represented by each of the five move types in details.

Move 5: Summarising research objectives and methods is to present the general information of the research design and research method of the study. Sometimes it is used to state or restate the research objectives of the study being reported. Move 5 was found to occur at the beginning of the Methods section and can be accomplished in possible two steps which are presented in the following.

Move 5, Step 1: Announcing research objectives/ questions is the segment where the authors address the objectives of the research, or the question(s) to be answered in the study.

This study sets out to investigate Thai students' attitudes towards the native-speaker and other ASEAN models in English pronunciation learning that highlight intelligibility with reference to the ideologies of ELF and EIL. Corresponding to the objective stipulated, the research question addressed in this study is: What are the Thai English learners' attitudes towards native-like pronunciation or the pronunciation of other varieties of English advocated by the nations of EIL, ELF, and WEs? [JES 2]

The above example focuses on the research objectives and research questions to be addressed in the study. The linguistic features of this move/step are rather formulaic, consisting of the use of to or in order to, followed by an infinitive verb form (investigate) to announce the research objectives of the study. The research questions can be listed in the form of an interrogative sentence.

Move 5, Step 2: Presenting research design serves to give an overview of the research design and/or approaches used to collect the research data. In this text segment, the authors might announce the research design of the study being reported before giving more details of the data collection process later in the Methods section. The position of this move/step is not fixed as it can be found anywhere in the section.

This study employed four qualitative research methods: in-depth interview, focus-group interview, documents and questionnaires. [LEA 3]

The predominant linguistic features used to identify and guide readers to the research design include the type or nature of research (qualitative research), and research methods or data collection techniques employed in the study (in-depth interview, focus-group interview, etc.). Linguistically, the use of past tense verbs, be they active or passive construction (employed, was employed) indicates the completion of the research activities in the study.

Move 6: Describing participants/ sources of data is to ostensibly describe the size of the sample of participants and their characteristics. Sometimes, the population, description of sampling technique, and representativeness of the sample are also provided. Specifically, this move can be realised by three possible steps: giving the description of the participants, justifying selection criteria, and defining research variables.

Move 6, Step 1: Providing the description of the participants/ data precisely reports the number of participants who took part in the research study being reported. Demographic information of the participants, including gender, age, and occupation, and the setting in which the research was carried out is also provided in this move/step.

The research population was the air hostesses and air steward in: first class, business class or economy class. The participants totalled $20 \mathrm{crew}$, both male and female. Their education background ranged from high school, to that of a Bachelor of Arts degree. [NET 4]

It can be seen that the presence of the word participants clearly serves to specify the information regarding the people selected in the study being reported. The description of the participants is precise and specific, providing their number, gender, and other characteristics. 
Move 6, Step 2: Justifying selection criteria draws attention to the rationale and/or criteria used in the selection of participants/data in the study. This move/step is used to assure readers that the potential participants or samples taking part in the study satisfactorily fulfil the requirements, serving appropriately the objective(s) of the study.

This target group was chosen for the following reasons. Firstly, they were the students of one researcher's friend; therefore, it was convenient to gather data. Secondly, with exposure English during lower and higher secondary school, it was assumed that they would have their own opinions on and effective ways of English learning. Also, because they were freshman English majors, they were useful for investigating and reflecting their possible formulated strategies to learn English at early undergraduate degree. [LEA 1]

As shown, the text example demonstrates some explicit reasons why the participants are selected to participate in the study. Linguistically, the subordinating conjunction because is used to imply a justification for selecting the participants in the study. The use of the past simple tense is quite dominant in this move/step. Other linguistic features used to indicate that the participants were selected wisely and systematically, serving the purpose of the study, are lexical items, such as the adjectives convenient and useful, and by listing the number of reasons through the use of firstly, secondly, and also.

Move 6, Step 3: Defining variables provides information about research variables. It is used especially with the experimental study looking at what research variables could affect the outcome.

Independent variables were the variable of person factor, the variable of family factor, and the variable of institution factor. Dependent variable was the characteristics of self-directed learning of the students from Faculty of Education, Silpakorn University. [VEJ 1]

The author can explicitly state research variables in Move 6, Step 3 by using words such as independent and dependent variable. This step is used because the author might need to guide and inform readers of the factors to be investigated in the study. This step can be realised by using past tense verbs (were, was).

Move 7: Stating research instruments centres on the features of the research instruments used. In this move, detailed information regarding research instruments used for particular research objective(s) is provided. This move is similar in use to that of the Move 6. Move 7 consists of two steps as below.

Move 7, Step 1: Detailing research instruments describes how research instruments are obtained, adapted, or created, pertaining to the particular objective(s) of the study. In Move 7, Step 1, the detailed description and/or characteristics of the instruments are also provided, and are sometimes presented with citations (Ref) if the study adopts or adapts the instruments from previous studies.

The Metacognitive Awareness of Reading Strategies Inventory (MARSI) designed by (Ref) was used to assess students' awareness and the use of reading strategies while they read. It consists of $\mathbf{3 0}$ items of metacognitive reading strategies.[SPPJ 1]

The author explains methods for measuring variables using lexical items related to research techniques for the collection of data in the study (e.g. questionnaire). In order to describe a methodological procedure, past tense verbs in passive constructions (was used, was adopted) are employed. The verbs was used and was adopted also entails some information regarding how the instruments are constructed, used, or developed in the study. The details of research tools used can also be elaborated.

Move 7, Step 2: Presenting the development/ justification of research instruments describes the process of implementing research instruments and/ or to provide justification for their choice, demonstrating how they are appropriate for the study being reported. In Move 7, Step 2, the selection of instruments is justified by their inherent characteristics and reasons why they were selected to be adopted, adapted, or developed in the study.

The initial version of the questionnaire was piloted before use with 30 first and second year students at the Faculty of Liberal Arts and Science of a public university in the second semester of 2012 academic year. The purpose of this piloting was to ensure that the language used in the questions was understood by the respondents, and the questions successfully elicited what they were supposed to. Based on the comments and feedback from the respondents, the questionnaire was revised accordingly. Some question items were rewritten, and others were elaborated to make sure that confusion was eradicated, and clarity enhanced.[JES 2]

The example text above reveals that perhaps the authors purposely tried to convince the readers that the choice of research instruments used appropriately served the purpose(s) of the study. Specifically, some 
lexical signals such as was piloted, to ensure, was revised, were rewritten, were elaborated, was eradicated, and clarity enhanced can markedly help state the justification for the instruments being used. Some lexical items are also used together with infinitive verbs (to ensure, to make sure), demonstrating the objective of the development of research instruments, which aids the authors to clarify the effectiveness and reliability of the instruments after some changes were wisely and appropriately made.

Move 8: Demonstrating research/data collection aims to selectively present data collection procedures in detail. Basically, Move 8 is used to convince readers that research activities in the study were systematically implemented in order to obtain reliable data for the analysis. In this move, the authors sometimes outline the procedures in ordering numbers, sometimes describe in statements.

Semi-structured interview was used to gather data related to students' voices on coherence, their writing, and their experience as writing students. The interviews questions were piloted with 15 English major students at another public university in a different region. Twelve students were individually interviewed in the final week of the course. The interview was audio recorded. Immediately after the interviews, the data were transcribed and then translated into English.

[LEA 4]

As shown in the instance above, Move 8 is marked overtly via a description of the research procedures and data collection in the study. It is important to note that most of the procedures described in this move were presented with past tense verbs, especially in the passive voice (was used, were interviewed, was recorded, was piloted, and was transcribed). It is possible that the author uses these to indicate that the study accomplished its task of addressing the objectives/ purposes established by following step-by-step the research activities mentioned.

Move 9: Describing data analyses is the last move of the Methods section, in which the authors present the method used to analyse the data obtained from the data collection process. To be precise, in quantitative research, the authors describe statistical devices used in the analysis and also justify analysis procedures by specifying why different statistical analyses are performed. Qualitative procedures may be sometimes described in this move. Move 9 was sometimes presented in ordering numbers, but sometimes not.

All of the returned questionnaires ( $N=387)$ were quantitatively analyzed by using the SPSS Statistics (SPSS) program for descriptive statistics in order to calculate mean rating and percentages, and to highlight any trends and significant commonalities, anomalies, etc. The Likert scale data analyzed by descriptive statistics provided a summary of data that not only identify the most popular answer for each question but also a group average.

[JES 2]

As shown, to inform discourse community members of data analysis procedures, this move emphasises approaches to analyse the data collected for the study, detailing statistical devices (descriptive statistics, mean rating, and percentages). Specific purposes for using statistical analysis are identified by the use of to, followed by infinitive verb forms (calculate, highlight). Similar to the characteristics of Move 8, to describe how the data analysis is conducted in the study, past tense verbs in the passive voice (were analyzed) are prevalently found in the RA Methods.

Table 2: Frequency of occurrence of moves and steps in research article Methods sections

\begin{tabular}{lcc}
\hline \multicolumn{1}{c}{ Move/Step } & \multicolumn{2}{c}{ Research Articles (N = 25) } \\
\cline { 2 - 3 } & Frequency & Per ent \\
\hline Move 5: Summarising research objectives and methods & $\mathbf{1 2}$ & $\mathbf{4 8 \% * * *}$ \\
Step 1: Announcing research objectives/ questions & 8 & $32 \%$ \\
Step 2: Presenting research design & 8 & $32 \%$ \\
Move 6: Describing participants/ sources of data & $\mathbf{2 5}$ & $\mathbf{1 0 0 \%}$ \\
Step 1: Providing the description of the participants/data & 25 & $100 \%$ \\
Step 2: Justifying selection criteria & 9 & $36 \%$ \\
Step 3: Defining variables & 2 & $8 \%$ \\
Move 7: Stating research instruments & $\mathbf{2 5}$ & $\mathbf{1 0 0 \%}$ \\
Step 1: Detailing research instruments & 25 & $100 \%$ \\
Step 2: Presenting the development/ justification of research & 11 & $44 \%$ \\
instruments & & $\mathbf{1 0 0 \%}$ \\
Move 8: Detailing research/ data collection procedures & $\mathbf{2 5}$ & $\mathbf{8 4 \%}$ \\
Move 9: Describing data analysis & $\mathbf{2 1}$ & \\
\hline${ }^{*}=$ Obligatory, ${ }^{* *}=$ Usual, ***Optional & &
\end{tabular}


Table 2 demonstrates that a set of five moves was not always used in the RA Methods. Moves 6, 7 and 8 were found in all 25 RAs (100\%), while Move 9 appeared relatively frequently (84\%). Move 5 is infrequent, as opposed to other moves, and thus is the least frequent move type. With respect to the frequency of each movement type, Moves 6, 7 and 8 are considered obligatory in performing their communicative functions in this particular section, while Move 9 is a usual move. Move 5 is regarded as a usual move. Based on their occurrences, it can be said that Moves $6,7,8$, and 9 play an integral role in the applied linguistics RA Methods sections. In contrast, the relatively low percentage of Move 5 indicates that summarising research objectives and research methods plays a much smaller role in Methods sections than it does in others.

\section{DISCUSSION AND CONCLUSION}

The analysis enables us to identify four major moves in the Introduction section, whereas five move types in the Methods section, which performs distinctive communicative functions. Some identified moves contain constituent steps which are infrequently found, whereas some steps are frequently present. With respect to the rhetorical pattern and function of the four moves identified in the Introduction sections, the findings of this study are partly congruent with Lakic's (1997) study focusing on RA Introductions in economics. The rhetorical structure of moves and steps generated by this study mostly is in resonance with Swales' (2004) Create-a-Research-Space (CARS) model for RA Introductions. Therefore, it is undeniable that his CARS model is quite successful, in both descriptive and pedagogic perspectives (Samraj, 2002). This indicates that Swales' model is worthwhile as a descriptive reference. Thus, it is likely that since Swales' three-move schema found in RA Introductions in many leading journals is relatively well-known and widely accepted among scholars, as witnessed by a plethora of research in this line, his suggested framework and model have become prototypical and have entered the consciousness of article authors. Moreover, because of its robustness in the field, the article authors in the analysis possibly know how to write an RA consistent with Swales' CARS model.

As for the Methods section, the typical functions of the five moves found in the present study are partially in agreement with Peacock's (2011) study focusing on 288 RA Methods sections in the eight academic disciplines of physics, biology, chemistry, environmental science, business, language and linguistics, law, and public and social administration. Moreover, the five move types identified in the present study are partly in agreement with Lim's (2006) study suggesting that three moves can be found in the Methods sections of RAs published in English in the discipline of management. They also partly conform to the three moves in Nwogu's (1997) study. Despite some common linguistic features and characteristics of these move types found in these studies, the presence of Move 5 in the current study is intriguing because it is the first move found in the Methods section in the discipline of applied linguistics. Apparently, the occurrence of Move 5 is not included in the model for the Methods section proposed by Lim (2006) and Nwogu (1997). This may well be due to the fact that the texts analysed in these studies are taken from different disciplines. Therefore, again, disciplinary variations can lead to the uniqueness of the organisational patterns of each discipline. The distinctive results yielded by the analysis also highlight the issue that the disciplinary communities constrain the rhetorical conventions of academic knowledge production (Hyland, 2004, 2009). At this juncture, this finding should be interpreted with caution because this move occurs less frequently compared to other moves in this particular section.

The results of the present study shed some light on how the target discourse communities of applied linguistics prefer a certain rhetorical structure. The awareness of rhetorical macro and micro-structural patterns is valuable to readers who encounter difficulties in understanding RAs, as well as to less experienced writers, especially Thai graduate students who need to understand the specific demands and expectations of writing for publication. In this regard, the awareness of prevailing rhetorical patterns bears some pedagogical usefulness. That is, since this study highlights to a certain extent the linguistic features that are commonly associated with the communicative functions of each rhetorical move found in these two sections, in EAP classes, the description of rhetorical structure and the characterisation of moves are pedagogically useful for the instruction of rhetorical elements, both moves and steps, and language use in writing an RA. In addition, classroom teachers can make full use of how to teach the linguistic features found in this study, providing students with authentic materials and how to effectively understand and use these sets of linguistic features in reading and writing classes or writing for publications. Finally, by extension, the knowledge from this study can be used in the development of academic reading and writing materials for advanced students, particularly Thai graduate students who wish to publish their research work in journals, especially those indexed in the $\mathrm{TCl}$ database. 


\section{REFERENCE LIST}

Basturkmen, H. (2012). "A Genre-Based Investigation of Discussion Sections of Research Articles in Dentistry and Disciplinary Variation". English for Academic Purposes. 11(2).

Biber, D., Conner, U., \& Upton, T. (2007). Discourse on the Move. Amsterdam: John Benjamins.

Bhatia, V. K. (1993). Analysing Genre: Language Use in Professional Settings. London: Longman.

Brett, P. (1994). "A Genre Analysis of the Results Section of Sociology Articles". English for Specific Purposes. 13 (1).

Bruce, I. (2008). "Cognitive Genre Structures in Methods Sections of Research Articles: A Corpus Study". English for Academic Purposes, 7 (1).

Canagarajah, A. S. (1996). "Nondiscursive Requirements in Academic Publishing, Material Resources of Periphery Scholars, and the Politics of Knowledge Production". Written Communication. 13 (4).

Cook, G. (1990). Discourse. Oxford: Oxford University Press.

Duenas, P. (2007). "Structure of Business Management Research Articles: The Methods Section". Odisea 8.

Flowerdew, J. (1999). "Writing for Scholarly Publication in English: The Case of Hong Kong". Journal of Second Language Writing 8.

Flowerdew, J. (2001). "Attitudes of Journal Editors to Non-Native Speaker Contributions". TESOL Quarterly, 35 (1).

Hyland, K. (2004). Genre and Second Language Writing. Ann Arbour: University of Michigan Press.

Hyland, K. (2009). "Writing in the Disciplines: Research Evidence for Specificity". Taiwan International ESP Journal. 1 (1).

Hyon, S. (2002). "Genre and ESL Reading: A Classroom Study". In A.M. Johns (Ed), Genre in the classroom: Multiple perspectives (pp. 121-141). NJ: Lawrence Erlbaum.

Kanoksilapatham, B. (2007). "Writing Scientific Research Articles in Thai and English: Similarities and Differences". Silpakorn University International Journal. 7.

Kanoksilapatham, B. (2011). "Language of Civil Engineering Introductions: Textual Structure and Linguistic Characterizations". The Asian ESP Journal 7 (2).

Kanoksilapatham, B. (2012). "Structure of Research Article Introductions in Three Engineering Subdisciplines". The IEEE Transactions on Professional Communication. 55 (4).

Lakic, I. (1997). "Genre Analysis of Article Introductions in Economics". ASP. 15 (18).

Lim, J.M.H. (2006). "Method Sections of Management Research Articles: A Pedagogically Motivated Qualitative Study". English for Specific Purposes. 25 (3).

McCarthy, M. (1991). Discourse Analysis for Language Teachers. Cambridge: Cambridge University Press.

Nwogu, K. (1997). "The Medical Research Paper: Structure and Functions". English for Specific Purposes, $16(2)$.

Ozturk, I. (2007). "The Textual Organization of Research Article Introductions in Applied Linguistics: Variability within a Single Discipline". English for Specific Purposes. 26 (1).

Peacock, M. (2011). "The Structure of the Methods Section in Research Articles across Eight Disciplines". The Asian ESP Journal. 7 (2).

Samraj, B. (2002). "Introductions in Research Articles: Variations across Disciplines". English for Specific Purposes. 21. 
Sombatsompop. N., Chancheewa, S., Markpin, T., Premkamolnetr, N., Ittiritmeechai, S., Wongkaew, C., Yochai, W., \& Ratchatahirun, P. (2012). "Thai -Journal Citation Index (TCI) Centre: 10 Years of Experiences, Lesson Learned, and Ongoing Development". Malaysian Journal of Library and Information Science.17 (3).

Swales, J. (1990). Move Analysis: English in Academic and Research Setting. Cambridge: Cambridge University Press.

Swales, J. (2004). Research Genres: Explorations and Applications. Cambridge: Cambridge University Press.

Wharton, S.M. (2006). "Given and New in TESOL Texts: The Management of Community Consensus and Individual Innovation". IRAL International Review of Applied Linguistics in Language Teaching. 44 (1).

Yang, R. \& Allison, D. (2003). "Research Articles in Applied Linguistics: Moving From Results to Conclusions". English for Specific Purposes. 22.

\section{APPENDIX}

\section{List of the names of the journals analysed in the study}

JLA Journal of Liberal Arts, Prince of Songkla University

SCOJ Scholar Journal

SJSH Silpakorn University: Journal of Social Sciences, Humanities, and Arts

NET The New English Teacher Journal

JES Journal of English Studies

VEJ Veridian E-Journal

LEA Language Education and Acquisition Research Network (LEARN) Journal 